\title{
Simple and Unadorned: Appreciation of Lepage's Haystack
}

\author{
Yangyu $\mathrm{Yu}^{1}$ \\ ${ }^{1}$ Academy of Fine Arts, Hunan Normal University, Changsha, Hunan, China \\ Corresponding author. Email:21000361342@qq.com
}

\begin{abstract}
In France in the middle and late 19th century, Romanticism, realism, Impressionism and other art styles were surging, and the painting world was noisy. In this era of various styles, Lepage kept a clear mind and insisted on the pursuit of realism. He insisted on the principle of "art for life" and reappeared the real face of French rural life at that time with simple and unadorned brushwork. He was known as the only painter who could truly and vividly reappear the hard life of French farmers after Miller.
\end{abstract}

Keywords: Lepage, realism, simplicity, art style

\section{BACKGROUND}

Throughout the development process of Western realistic painting, Lepage's painting is unique in this process. In the 1870 s, European realistic painting was no longer regarded as the mainstream painting school, and realistic painting began to go to a low ebb in France. A large number of artists began to choose their own direction again, some went to symbolism or chose Impressionism. However, there are still some painters who follow the realistic creative principles, often go to the countryside and the bottom of society to collect creative themes. They stick to the realistic creative position, firmly follow the principle of "art for life and for the common people", concentrate on their own artistic ideas, and focus on the description of real life. Lepage is one of them.

"Jules Bastien-Lepage was born in 1848 in a small village on the banks of the Moz River in MUZ Province, France."[1] His father was a farmer and his family conditions were good. Lepage spent his childhood in this beautiful village, which made Lepage very familiar with the countryside and farmers since childhood, and had deep feelings for rural life. Lepage liked painting since he was a child. His father supported him to learn painting very much and bought a lot of printing materials for him to learn. Later, when he was a little older, Lepage was sent to Verdun to study. From then on, he began to receive formal art training. In 1867, Lepage came to the Paris Academy of fine arts and carried out strict academic training under the guidance of the famous academic master Cabagnel at that time. Three years of hard work has brought up his solid painting skills. His teacher, Barnier, inherited from angel, not only absorbed angel's preciseness and delicacy, but also absorbed the drama and lyricism in romantic painting, forming his own unique appearance. Deeply influenced by his teacher Barnier's paintings, Lepage also comes into contact with works of romanticism, realism and Impressionism, which makes him take rigorous observation and expression of nature as his artistic pursuit. His works are not only rigorous modeling, but also full of romantic atmosphere and strong appeal.

In 1878, Lepage created " haystack" (Figure 1), which is his most representative work of local naturalism style. Stacking grass depicts a couple of farmers resting in the shade of trees beside the farmland. Because of the hard

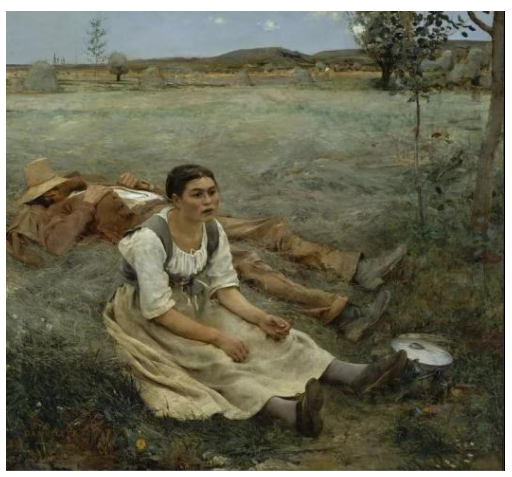

Figure 1 haystack. 
work and overwork in the morning, the farmer lay down on the grass and slept soundly. He covered his face with an old straw hat, and his clothes and shoes were worn out. We could see that he was very thin. The farmer's wife sat next to him. She came to deliver food to her husband, who had obviously eaten. She gazed ahead, tired and numb by long hard work. Lepage vividly depicts the mental state of a peasant couple under the pressure of life with superb realistic skills. He did not choose to depict the scene of the couple's work, but chose the scene of their rest, which is the artist's brilliant point. By depicting the tired state of the farmers during the rest, he emphasized the hard work and hard life. Lepage was less than 30 years old when he created this painting, which shows the artist's superb painting skills and profound thinking. The inspiration of Lepage's creation of this painting comes from a poem expressing the countryside: "lying on the soft grass in the field, the Reaper tanned by the sun, with the hardship and fatigue of life, clenching her fist and sleeping peacefully, while she sits beside him blankly, physically and mentally exhausted..."[2] This painting truly shows the hard life of rural farmers at that time.

\section{A CLOSE LOOK AT THE STACK OF GRASS}

"In 1878, haystack was a great success in the Salon Exhibition"[3], and Lepage became famous. When romanticism, realism, Impressionism and other art styles are surging up, Lepage still sticks to local painting, depicts the living conditions of laborers and expresses his concern for farmers. Lepage is a staunch of realism. He has a profound understanding of rural life and the life of the French bottom farmers. He sticks to the countryside, pays attention to the peasants' living conditions, and arouses the society's attention to them through the real description of the peasants' living conditions.

The characters in haystack are rigorous and vivid in modeling, which is due to the solid foundation of studying painting in Paris in his early years. Lepage arranged the characters in the fresh nature to depict, the open grass, the distant grass and mountains, and the small trees standing quietly make the outline of the couple clearer.

In terms of color, Lepage absorbed the color processing skills of Impressionism, but did not pursue the instant light and color as the Impressionist painters did. Instead, he chose a more rational processing method. In the picture, there was no particularly dazzling color. He organized all kinds of color relations in an orderly way, the colors were bright and transparent, the contrast between cold and warm was very accurate, and the tone was very unified. In haystack, Lepage uses transparent painting to deal with the farmer's face, which makes the color level of the farmer's face very rich. His rigorous use of color habits, make it easy to grasp the tone, so that his picture reflects a strong expression and appeal.

In shaping, Lepage has admirable shaping ability, he can refine and accurately shape all kinds of characters and images he wants to describe. The characters depicted in haystack are very vivid. As a result of hard work, the farmer lies down and sleeps soundly after eating the lunch sent by his wife. The peasant woman sitting quietly beside her husband bends her back, and can feel that she is very tired. The state of staring at the front with dull eyes is vividly depicted by the painter. There are a lot of details in the picture, such as the soil in the nail, the weeds in the hair and the description of the lunch box. All of these are captured by the artist's keen eyes and truly displayed, which can show us the difficult living conditions of the peasant couple under the heavy pressure of life.

Lepage is also very particular about composition. It took a lot of effort from the beginning of creation to the final completion of this work. After several times of deliberation and several changes of manuscript (Figure 2 ), we found the best composition, which is what we can see now. Lepage first put the farmer couple in a large space, the position of the characters was reasonable, and the space treatment was far-reaching.
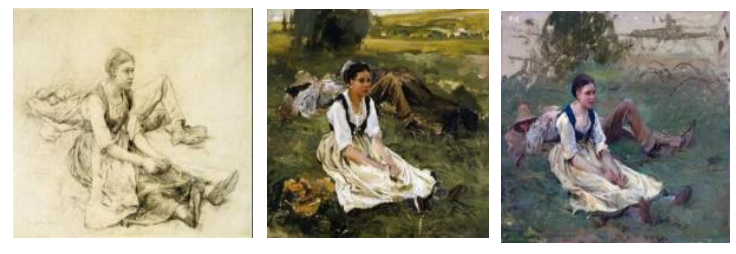

Figure 2 manuscripts of haystack.

The movement of the characters in the picture tends to be consistent, and their hands and feet intersect. The relationship between the characters is well arranged. The visual center of the painting is focused on the farmer's eyes, which convey all the information to the viewer. The farmer's slightly open mouth is very vivid and natural. Her slightly curved back plays a great role in supporting the composition of the picture. Lepage exhausted all means to express things, accumulated all energy, only to serve the visual center. Her eyes are also the only "Language Center" in the picture. Her eyes always have a kind of backward extension. It seems that there are memories in her eyes, but everything is difficult to express with language. The composition found the balance point of the characters. There was a big tree on the right. For the sake of composition, Lepage only drew a small part. In order to avoid too much to grab the main relationship of the characters in the picture, the picture has four sides, such a choice, the composition of hanging corners will accumulate a lot of power. The character lying on his back covers the whole lower left corner. His legs are parallel and low, and he 
naturally sits on the ridge of the field. When he falls asleep relaxed, he also shows extreme fatigue. Such relaxation can also reflect the hard work. Blooming wild flowers, clear mountains and clear sky not only set off the atmosphere of the picture, but also enrich the readability of the picture. All the elements of the picture, whether it is the choice of image or the environment matched with it, are completely derived from and faithful to life, with a strong reflection of life and full of moving power. It is his research on the composition that leads to the creation of this masterpiece, which truly shows the living conditions of French rural farmers in the 19th century.

\section{THE INFLUENCE OF DUOCAO ON CHINA}

Haystack has been exhibited twice in China. The first one was the "French 19th century rural landscape painting exhibition" held in Beijing in March 1978. At that time, China had just finished the "Cultural Revolution". The works on display made the audience immediately brighten up, greatly promoted the shift of oil painting creation after the cultural revolution, provided a new "realistic" sample for Chinese oil painting at that time, and set off a nationwide movement. There is a fever of nostalgia and local customs. Among them, Cheng Conglin's works "snow" on 1968 (Fig. 3), he duoling's works "we used to sing this song" (Fig. 4), Chen Danqing's works "Tibetan" (Fig. 5) and Luo Zhongli's works "father" (Fig. 6) are the most prominent. The second is the exhibition of "Miller, Courbet and French naturalism - Musee d'Orsay in Paris" held in Shanghai in 2012. Haystack came to China twice, which caused a great shock in the painting world and influenced a large number of Chinese painters.

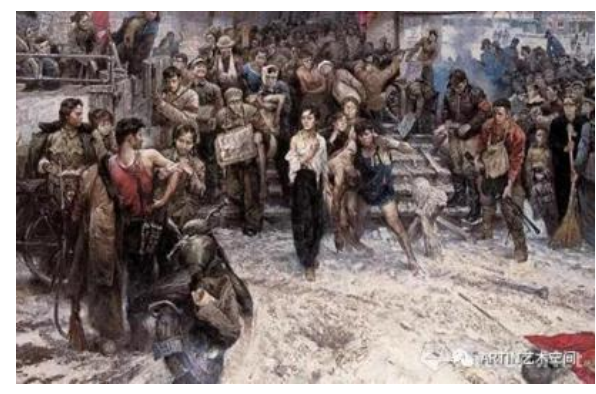

Figure 3 snow on 1968

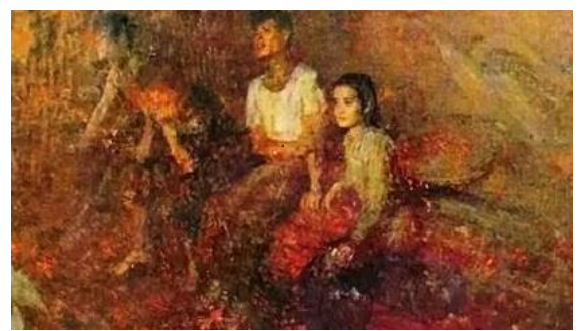

Figure 4 we used to sing this song

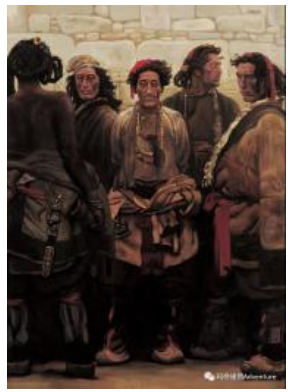

Figure 5 Tibetan.

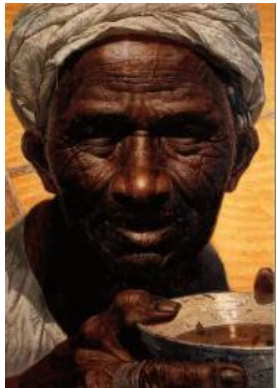

Figure 6 Father
China is a large agricultural country. Farmers play an irreplaceable role in promoting China's development and progress. They have cultivated in this fertile land for generations, forming a unique culture in rural China. They have deep feelings for the land. Many Chinese artists have found a new way of oil painting creation through Lepage and other works in the exhibition. More and more artists begin to learn from Lepage's "realism" style and the display of his humanistic spirit in artistic creation. They are more active in exploration and practice. Many of them have lived in the countryside. They have learned a lot from the farmers, understood different local conditions and customs, and provided rich materials for their artistic creation. Farmers are the lowest labor groups in the society. The humanistic care for farmers will be expressed through art forms, giving new colors to the times, making artists more accepted and concerned by the public, and better serving the people.

The development of contemporary Chinese local oil painting has initially focused on the sincere feelings of the working people and turned to explore the rural humanistic spirit and the national spirit behind it. The artistic spirit and artistic creation techniques of Lepage have a far-reaching impact on the development of Chinese local oil painting. With the development of diversified exchanges in the world, this impact will continue to be far-reaching and lasting.

\section{CONCLUSION}

As one of the most outstanding realistic painters in France at the end of the 19th century, Lepage firmly followed the principle of "art for life, art for common people", which became his unique painting concept. He is well-known for his performance of farmers' themes and reflection of social reality. His local oil paintings have extraordinary significance in the history of Western art. The theme of his works follows the principle of realism and draws materials from social reality. By focusing on the working people at the bottom of the French society, Lepage made art not only a tool to serve the upper class, but also a medium to express the life and mental state of ordinary people. 
Lepage's paintings are full of human concern for reality. This is not only the result of Lepage's accumulation, thinking and summary of life, but also the result of learning from others and constantly improving himself. Based on the reality, his art inherits the rigorous and meticulous advantages of academicism, and absorbs the nutrients of Impressionism in exploring the law of outdoor light and color. His works are full of deep concern for the spiritual world of workers. This is a remarkable characteristic that distinguishes him from other contemporary painters.

The emergence of Lepage's realistic painting is not a historical accident, his art in that era is a fusion of art, adding a new look and form of expression for realistic painting. He is loyal to the creation of rural themes, sincerely praises and praises labor, and pays attention to the working people at the bottom of society. "His paintings are influenced by classicism and absorb the advantages of Impressionism, inheriting and developing realism, forming his own unique artistic appearance, and showing realistic paintings in a new form "[4]. His works of art set a new benchmark for the development of realistic painting. He advocates "art for the common people" and opposes the pure formalism of art for the sake of art. His works are full of expression of "human nature". His works are sincere and his pictures contain humanistic care for ordinary people.

\section{REFERENCES}

[1] Shi Zhongya. Research on French realistic painting in the 19th century $[\mathrm{J}]$. Popular literature and art, 2017 (20): 77

[2] Guo Wenning. Simple description_Lepage's native naturalistic painting [J]. Grand View of fine arts, 2016 (02): 4-11

[3] GuaAndre, Theuriet, Clausen, George. JULES BASTIEN-LEPAGE AND HIS ART A MEMOIR [M]. Kessinger legacy reprints, 2010, p47.

[4] Tian Zhen. On Bastion_ Leparer realism painting [D]. Shandong: Qufu Normal University, 2018 